\title{
Combining volunteers and primary care teamwork to support health goals and needs of older adults: a pragmatic randomized controlled trial
}

\author{
Lisa Dolovich PharmD MSc, Doug Oliver MD, Larkin Lamarche PhD, Lehana Thabane PhD, Ruta Valaitis PhD, \\ Gina Agarwal MBBS PhD, Tracey Carr MBA RN, Gary Foster PhD, Lauren Griffith PhD, Dena Javadi MSPH, \\ Monika Kastner PhD, Dee Mangin MBChB, Alexandra Papaioannou MD, Jenny Ploeg PhD, Parminder Raina PhD, \\ Julie Richardson PhD, Cathy Risdon MD, Pasqualina Santaguida PhD, Sharon Straus MD MSc, David Price MD
}

Cite as: CMAJ 2019 May 6;191:E491-500. doi: 10.1503/cmaj.181173

See related article at www.cmaj.ca/lookup/doi/10.1503/cmaj.190406

\begin{abstract}
BACKGROUND: The Health TAPESTRY (Health Teams Advancing Patient Experience: STRengthening QualitY) intervention was designed to improve primary care teamwork and promote optimal aging. We evaluated the effectiveness of Health TAPESTRY in attaining goals of older adults (e.g., physical activity, productivity, social connection, medical status) and other outcomes.
\end{abstract}

METHODS: We conducted a pragmatic randomized controlled trial between January and October 2015 in a primary care practice in Hamilton, Ontario. Older adults were randomized $(1: 1)$ to Health TAPESTRY $(n=158)$ or control $(n=154)$. Trained community volunteers gathered information on people's goals, needs and risks in their homes, using electronic forms. Interprofessional primary care teams reviewed summaries and addressed issues. Participants reported goal attainment (primary outcome), self-efficacy, quality of life, optimal aging, social support, empowerment, physical activity, falls, and access to and comprehensiveness of the health system. We determined use of health care resources through chart audit.

RESULTS: There were no differences between groups in goal attainment or many other patient-reported outcome and experience assessments at 6 months. More primary care visits took place in the intervention versus control group over 6 months (mean \pm standard deviation [SD] $4.93 \pm 3.86$ v. $3.50 \pm 3.53$; difference of 1.52 [95\% confidence interval $(\mathrm{Cl}) 0.84$ to 2.19]). The odds of having 1 or more hospital admission were lower for the intervention group (odds ratio [OR] 0.44 [95\% Cl 0.20 to 0.95]).

INTERPRETATION: Health TAPESTRY did not improve the primary outcome of goal attainment but showed signals of shifting care from reactive to active preventive care. Further evaluation will help in understanding effective components, costs and consequences of the intervention. Trial registration: ClinicalTrials.gov, no. NCT02283723 ountries with well-functioning primary care systems have realized better health outcomes and health equity. ${ }^{1,2}$ Health care systems worldwide are rearranging primary care to be proactive versus reactive, to focus on prevention rather than disease, to better connect to health and social care, to attend to multimorbidity, and to emphasize individualized whole-person, team-based and flexible care adjusted community needs..$^{3-5}$ Canada is among the countries remodelling primary health care ${ }^{6}$ including adoption of interprofessional health care teams. ${ }^{7-9}$
The Health TAPESTRY (Health Teams Advancing Patient Experience: STRengthening QualitY) intervention was designed to improve person-centred and team-based primary care. It combines new health care elements with strengths of the current system. The program promotes principles of optimal aging through components that aimed to improve system navigation, include use of trained volunteers, enhance interprofessional primary care teams, and use new in-home technologies and community engagement to plan care based on participants' goals, risks and needs. 
Each component is supported by evidence of effectiveness., ${ }^{80-20}$ However, we are unaware of any initiative that evaluates the integration of program components. As support from health care volunteers is therapeutic to patients, ${ }^{21}$ Health TAPESTRY broadened the concept of the health care team to include volunteers who link to primary care in ways comparable to community or lay health worker activities. ${ }^{22,23}$ This study applies the Health TAPESTRY intervention to older adults, a growing proportion of the population ${ }^{24}$ who are the highest consumers of health care spending ${ }^{25}$ and thus an increasing focus of activity within primary care.

The primary research question was "What is the effectiveness of the Health TAPESTRY intervention on the identification and attainment of a person's health goals in older adult participants compared with people not receiving the Health TAPESTRY intervention after 6 months?" Our hypothesis was that Health TAPESTRY would allow people to attain their health goals more effectively. Secondary research questions addressed patient-reported outcomes and experiences and use of health service resources.

\section{Methods}

\section{Design and setting}

We conducted an unblinded, pragmatic randomized controlled trial (RCT) that included a delayed intervention to encourage recruitment by providing opportunity for all participants to receive the intervention eventually (Figure 1 ). The trial protocol was published..$^{26}$ We conducted the study at the 2-site McMaster Family Health Team, a multidisciplinary academic primary care team in Hamilton, Ontario, serving about 37000 patients.

\section{Participants}

Patients were rostered with the McMaster Family Health Team, aged 70 years or older, and living in Hamilton. We excluded patients if they were away for more than $50 \%$ of trial duration, in long-term care, palliative, or neither they nor a family member spoke English. We did not target any specific diseases or levels of health. We identified potential patients using electronic medical records, then family physicians screened these patients for exclusions. We sent invitation letters to eligible patients. Recruitment occurred between Jan. 23 and Oct. 30, 2015.

\section{Randomization and concealment}

A statistician external to data collection managed an automated, central (allocation concealed) computerized randomization sequence (Appendix 1, available at www.cmaj.ca/lookup/suppl/ doi:10.1503/cmaj.181173/-/DC1). The patient was the unit of randomization. Randomization was stratified by gender and clinical site and blocked. Couples were accepted as 1 unit, with both members randomized into the same group but only 1 of the pair was randomly selected for the main analysis. Dropouts were not replaced.

We did not tell patients, caregivers and volunteers whether patients were in the initial or delayed intervention group. Health care team members knew a patient was receiving the intervention once a Health TAPESTRY report was reviewed but were masked (not blinded) to allocation. Research staff had access to files identifying patient randomization status.

\section{Intervention and control groups}

We designed the multicomponent and multistage intervention with the participation of patients, volunteers, health care providers and community representatives. ${ }^{27}$ Details of the intervention are provided elsewhere. ${ }^{26}$ Each patient received a home visit from a pair of trained community volunteers who collected information using an electronic data collection software tool (TAP-App) on a tablet computer. They collected information on life and health goals, risks and needs, daily life activities and general health, using structured surveys and unstructured narratives. Structured surveys were chosen if they were valid, reliable, feasible and free of cost. ${ }^{28}$ The volunteers sent, securely and electronically, a report summarizing patients' goals, alerts, key issues and observations to the primary care electronic medical record, to the attention of an intake and case conferencing interprofessional "huddle" team at the clinics. These interprofessional teams reviewed the reports and then generated, prioritized and acted upon plans of care for how the team (including non-huddle-team members), community agencies and volunteers could address clients' goals and health issues, with iterative follow-up. Interprofessional teams included combinations of health care professionals. Each team defined their workflow processes. Team members did not overlap between study sites.

We recruited volunteers using email and printed brochures distributed to community organizations and university groups, newspaper advertisements, a volunteer opportunity website and word of mouth. ${ }^{29}$ Volunteer training consisted of 11 online modules, an initial 2-hour face-to-face session and 9 additional sessions during the intervention. ${ }^{29}$ The intervention period was 6 months.

The control group received usual care and did not have volunteer visits. There was no restriction on receiving care from the same team members as the intervention group; however, control patients were not discussed at huddle groups.

We followed patients in both groups throughout implementation and at 6 months. Clinical follow-up was determined according to patients' needs. We gathered baseline data using selfreport surveys, electronic medical records and TAP-App. We collected intervention participant surveys used in health care team reports using the TAP-App. We programmed outcome surveys into REDCap (version 6.9.7). We used a pilot-tested form for the abstraction of electronic medical records data; this was done independently, in duplicate, until there was agreement between trained research assistants (i.e., $\mathrm{k}$ statistic of $\geq 0.70$ ).

\section{Outcomes}

The primary outcome was goal attainment as determined by goal attainment scaling at 6 months. Goal attainment scaling is based on attainment of individual health goals, using the mean difference of scores between groups from baseline. ${ }^{30,31}$ Patients identified their health goals, indicators and outcomes through piloted, structured, prompted discussion with trained volunteers in the intervention group or similarly trained research staff in the control group. The development of the goal-setting processes used has been published. ${ }^{32}$

Secondary outcomes evaluated were self-efficacy; ${ }^{33}$ quality of life; ${ }^{34}$ perception of optimal aging (4-point scale) $;{ }^{35}$ social support; ${ }^{36}$ 
caregiver strain; ${ }^{37}$ satisfaction with health care (10-point scale); access; ${ }^{38}$ comprehensiveness; ${ }^{38}$ patient empowerment; ${ }^{38}$ patientcentredness; ${ }^{38}$ physical activity; ${ }^{39,40}$ falls; and primary care, hospital and emergency department visits for any reason. To gain further insight into hospital admissions, and recognizing that categories overlap, unblinded research staff categorized hospital admissions into (a) ambulatory care-sensitive conditions for chronic disease $\mathrm{e}^{41}$ and (b) adverse effects. All outcomes were listed elsewhere, ${ }^{26}$ except that post hoc we also examined the proportion of participants' self-reporting maintenance or improvement in their top priority goal, and medication use, as huddle groups reported particular attention to medication reduction. Subgroup analyses were conducted on all outcomes.

We gathered information on critical incidents, including possible adverse events, through passive surveillance from trial personnel using a structured form. A family physician directed follow-up. We did not create definitions for anticipated or unexpected adverse events a priori.

\section{Sample size}

To find a mean difference of 5 points on goal attainment scaling score signifying improvement in level of goals attained in intervention versus control, and assuming a baseline goal attainment scaling score of 30 , standard deviation (SD) of 15 , power of $80 \%$ and type I error probability of 0.05 , we had to enrol 286 patients. This difference was shown to be an achievable and meaningful change when we triangulated data from studies using goal attainment scaling in older adults. ${ }^{42-44}$ Planned subgroup analyses were exploratory. We aimed to enrol 316 participants to account for $10 \%$ loss to follow-up.

\section{Statistical analysis}

Baseline characteristics are reported by group as mean ( \pm SD) for continuous variables and count (percent) for categorical variables. The primary between-group comparisons occurred at 6 months and was intention-to-treat for all outcomes. We performed a perprotocol sensitivity analysis for the primary outcome.

We used multiple imputation for missing data to enable intention-to-treat analyses. ${ }^{45}$ We analyzed data using multiple linear regressions for continuous variables and logistic regressions for categorical variables, adjusting for baseline scores or events. For continuous outcomes with skewed distributions, data were transformed and analyzed using analysis of covariance. Baseline-adjusted odds ratios (ORs) with corresponding 95\% confidence intervals (Cls) from logistic regression were reported for dichotomous outcomes. Baselineadjusted incidence rate ratios with corresponding 95\% Cls were reported for count variables. The criterion for statistical significance was set a priori at $\alpha=0.05$. Subgroup analyses examined differences between men and women; age younger than 80 , and 80 years and older; individuals residing alone or with others; or those with fewer than 3 , or 3 or more chronic conditions. We used SAS version 9.4.
Before randomization - Iterative pilot testing - Volunteer recruitment and training

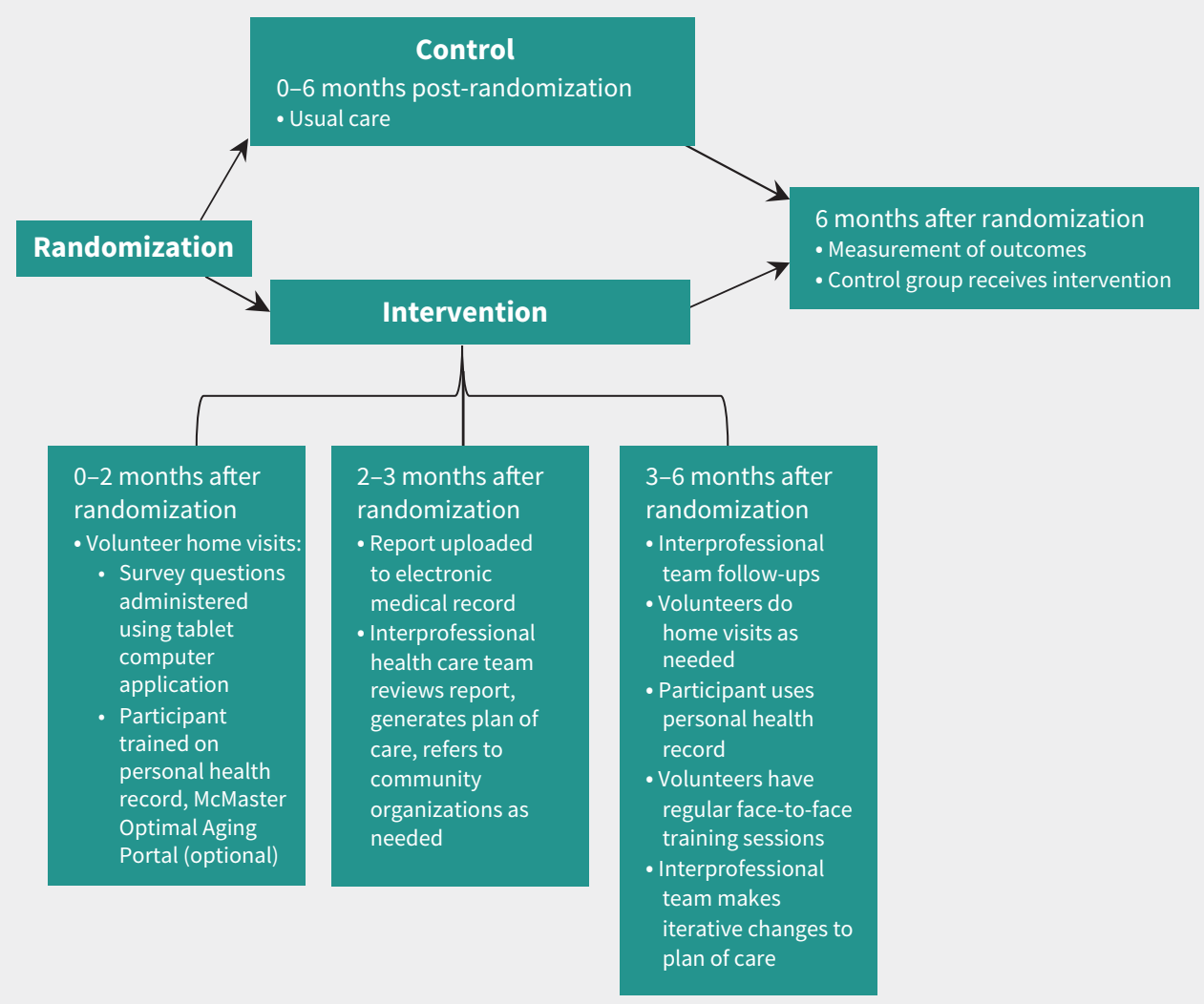

Figure 1: Study design and description of Health TAPESTRY intervention. 

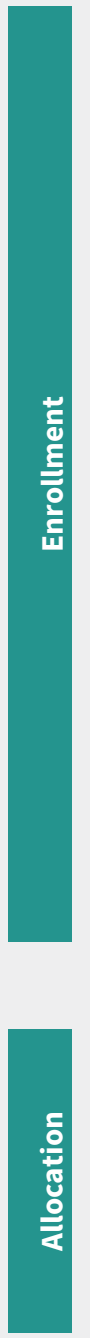

Allocated to intervention $n=158$

- Received allocated

intervention $n=157$

- Did not receive allocated

intervention $n=1$ (report

never sent to clinic before

follow-up because of

scheduling challenges)

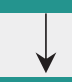

Lost to follow-up $n=6$

- Passed away $n=1$

- Decided not to start $n=5$

Discontinued intervention $n=14$

- Disappointed with program or

too much follow-up $n=6$

- Too busy $n=3$

- Health problems $n=1$

- No reason given $n=4$

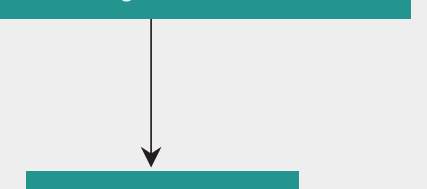

Analyzed $n=158$ $n=360$

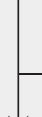

Excluded $n=583$

- Excluded by physician $n=222$

- Geography exclusion $n=361$

No response to consent $n=1393$

Returned consent $n=605$

- Declined to participate $n=137$

- Did not meet inclusion criteria $n=37$

- Could not be reached $n=71$

\section{Participants enrolled}

articipants randomized $n=312$

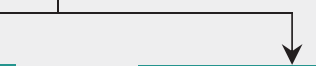

Allocated to control

$n=154$

- Received allocated

intervention $n=154$

- Did not receive allocated

intervention $n=0$

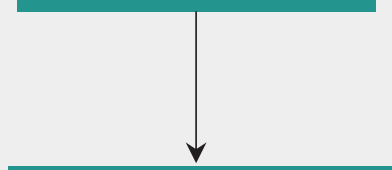

Lost to follow-up $n=6$

- Passed away $n=2$

- Decided not to start $n=5$

- Never reached $n=1$

Discontinued intervention $n=8$

- Too busy $n=3$

- Changed doctors $n=1$

- Problems with health or personal

life $n=2$

- Disappointed with questions $n=1$

- No reason given $n=1$

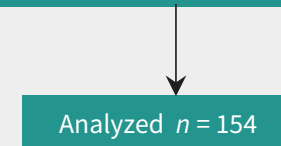

Participants of couples not included in main analysis $n=48$
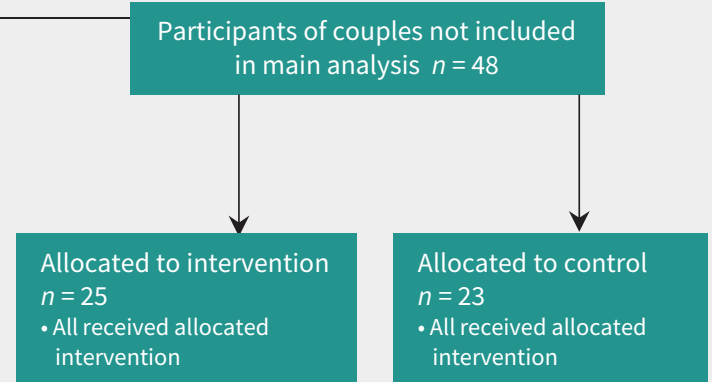

intervention

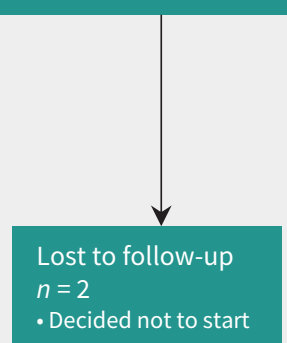

Analyzed $n=25$

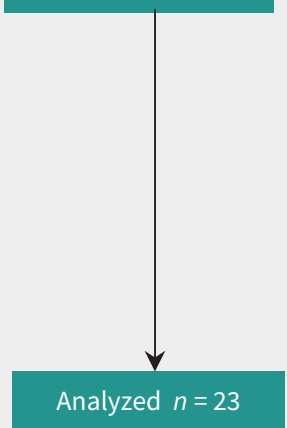

Figure 2: CONSORT 2010 flow diagram. 


\section{Ethics approval}

This study was approved by the Hamilton Integrated Research Ethics Board.

\section{Results}

Physician screening reduced potential participants from 2581 to 1998 . Consent was received from 605 respondents (30\% response rate). Of these, 360 people were enrolled, representing 312 units randomized (264 individuals and 1 member from 48 couples, resulting in 158 intervention and 154 control participants) (Figure 2).

Groups were well balanced on most characteristics (Table 1), except that the intervention group had a slightly lower age, higher level of education, and slightly fewer comorbidities.

There was no statistically significant between-group difference in goal attainment scaling score (57.79 intervention v. 58.94 control group, respectively; adjusted mean difference -1.50 [95\% Cl -6.51 to 3.50$]$ ). A goal attainment scaling score $>50$ showed that both groups had made progress toward attaining goals compared with baseline. The number of goals in the intervention group was 414 ( $n=158$; mean 2.62) and the number of goals in the control group was 378 ( $n=154$; mean 2.45). The most common highest-priority goal areas identified were related to physical activity, productivity, social connection and maintaining health (Table 2). A per-protocol sensitivity analysis (57.62 intervention v. 58.94 control, $p=0.6$ ) did not change results.

There were no statistically significant between-group differences in participant ratings of self-efficacy, quality of life, optimal aging, social support, patient empowerment, or perceived access to, or comprehensiveness of, the health care system (Table 3).

There was a statistically significant between-group difference in self-reported time walking per week; an increase of 81 minutes in the intervention versus decrease of $120 \mathrm{~min}$ utes in the control groups $(p=0.004)$. There were no statistically significant between-group differences in other aspects of physical activity, although higher levels were reported by the intervention group for all physical activity categories. Suboptimal physical activity scores (i.e., $\leq 600$ metabolic equivalent of task min/wk) were reported in $24.3 \%$ of the intervention group and $32.8 \%$ of the control group at 6 months. While fewer people in the intervention group
Table 1: Participant characteristics

\begin{tabular}{|c|c|c|}
\hline Variable & $\begin{array}{l}\text { Intervention, } n(\%)^{\star} \\
\quad n=158\end{array}$ & $\begin{array}{c}\text { Control, } n(\%)^{\star} \\
n=154\end{array}$ \\
\hline Female† & $101(63.9)$ & $93(60.4)$ \\
\hline Age, $y r$, mean \pm SD $\dagger$ & $78.06 \pm 6.3$ & $79.06 \pm 6.6$ \\
\hline Age $>80 \dagger$ & $54(34.2)$ & $64(41.6)$ \\
\hline Highest level of education $†$ & $n=153$ & $n=145$ \\
\hline High school & $60(38.0)$ & $70(45.5)$ \\
\hline Post-secondary and higher & $93(58.9)$ & $75(48.7)$ \\
\hline Country of birth: Canada $†$ & $\begin{array}{c}83(59.3) \\
n=140\end{array}$ & $\begin{array}{c}84(60.9) \\
n=138\end{array}$ \\
\hline European or white ethnicity $\dagger$ & $\begin{array}{c}111(88.8) \\
n=125\end{array}$ & $\begin{array}{c}109(86.5) \\
n=126\end{array}$ \\
\hline Main language: English† & $\begin{array}{c}131(94.2) \\
n=139\end{array}$ & $\begin{array}{c}126(91.3) \\
n=138\end{array}$ \\
\hline Marital status $\dagger$ & $n=137$ & $n=134$ \\
\hline Married or common law & $70(51.1)$ & $66(49.3)$ \\
\hline $\begin{array}{l}\text { Widowed, divorced, separated, } \\
\text { single or never married }\end{array}$ & $67(48.9)$ & $68(50.8)$ \\
\hline Chronic conditions or diseases $\ddagger$ & & \\
\hline Hypertension & $\begin{array}{c}81(66.9) \\
n=121\end{array}$ & $\begin{array}{c}88(66.7) \\
n=132\end{array}$ \\
\hline Osteoarthritis & $\begin{array}{c}43(35.3) \\
n=122\end{array}$ & $\begin{array}{c}61(46.2) \\
n=132\end{array}$ \\
\hline Diabetes & $\begin{array}{c}37(30.3) \\
n=122\end{array}$ & $\begin{array}{c}34(25.8) \\
n=132\end{array}$ \\
\hline Heart disease§ & $\begin{array}{c}41(33.6) \\
n=122\end{array}$ & $\begin{array}{c}57(43.2) \\
n=132\end{array}$ \\
\hline Cancer & $\begin{array}{c}26(21.9) \\
n=119\end{array}$ & $\begin{array}{c}40(30.3) \\
n=132\end{array}$ \\
\hline $\begin{array}{l}\text { Chronic obstructive pulmonary } \\
\text { disease or lung disease }\end{array}$ & $\begin{array}{c}14(11.9) \\
n=118\end{array}$ & $\begin{array}{c}18(13.6) \\
n=132\end{array}$ \\
\hline $\begin{array}{l}\text { Stroke or cerebrovascular } \\
\text { disease }\end{array}$ & $\begin{array}{l}8(6.6) \\
n=122\end{array}$ & $\begin{array}{l}8(6.1) \\
n=131\end{array}$ \\
\hline Extent of comorbidity $\ddagger$ ฯ & $n=122$ & $n=132$ \\
\hline 1-2 comorbidities & $86(70.5)$ & $85(64.4)$ \\
\hline$\geq 3$ comorbidities & $36(29.5)$ & $47(35.6)$ \\
\hline Years with clinic $\ddagger$ & $n=158$ & $n=153$ \\
\hline$<5$ & $28(17.7)$ & $23(17.0)$ \\
\hline$\geq 5$ & $130(82.3)$ & $127(83.0)$ \\
\hline $\begin{array}{l}\text { No. of prescription medications, } \\
\text { mean } \pm \text { SD } \ddagger\end{array}$ & $\begin{array}{c}5.39 \pm 4.2 \\
n=156\end{array}$ & $\begin{array}{c}5.64 \pm 3.8 \\
n=150\end{array}$ \\
\hline \multicolumn{3}{|c|}{$\begin{array}{l}\text { Note: } n=\text { number used in the analysis, SD = standard deviation. } \\
\text { *Unless stated otherwise. } \\
\text { †Self-report data source. } \\
\text { †Chart audit data source. } \\
\text { §Conditions such as arteriosclerosis, angina pectoris and heart failure. } \\
\text { IBased on list of conditions above. }\end{array}$} \\
\hline
\end{tabular}


Table 2: Description of the types of goals identified by participants

\section{Goal area}

Physical activity

Productivity

Social connection

Medical

Maintainance of

health

Diet and nutrition

Other

Rehabilitation

Mental health

Smoking and use

of alcohol

Total goals set

\section{General goal examples*}

Exercising more, walking more, starting a new activity, maintaining current physical fitness levels, getting out and getting more active
Intervention group, $n(\%) \dagger$

$n=158$

$78(18.84)$

$70(16.91)$

$60(14.49)$

$51(12.32)$

$48(11.59)$

$36(8.70)$

$29(7.00)$

$26(6.28)$

$13(3.14)$

$4(<1)$

414
Total sample, $n(\%) \dagger$ $n=312$

$142(17.93)$

$130(13.41)$

$113(14.2)$

98 (12.37)

$111(14.02)$

$47(5.93)$

$60(7.58)$

47 (5.93)

$20(2.53)$

$4(<1)$

792

*Through further discussion, each general goal was expressed more specifically by a participant as specific actions over a specific time frame to achieve the goal. The participant identified the goal as an ideal yet possible target for achieving the goal by considering the question: "In 6 months, what specifically would be the biggest change you would want to see?". The SMART goals format was used to create specific, measurable, attainable, relevant, and timely goals. Progress toward goal achievement was rated based on 5 expected outcome levels for each goal identified.

†Percentages relate to the percentage of total goals set.

( $n=10,6.33 \%)$ had 1 or more falls, this difference was not statistically significantly different from the control group $(n=19$, $12.34 \%$; OR 0.47 [95\% $\mathrm{Cl} 0.21$ to 1.05$])$.

The number of primary care visits increased in the intervention group; a mean \pm SD of $4.93 \pm 3.86$ visits in the intervention group compared with $3.50 \pm 3.53$ visits in the control group; and a baseline-adjusted absolute difference of $1.52(95 \% \mathrm{Cl} 0.84$ to 2.19). Increased visits were not only with physicians, but also included visits to other interprofessional team members. For example, while $57.7 \%$ of intervention participants had follow-up with physicians, $35.6 \%$ and $30.9 \%$ of participants had follow-up with occupational therapists and dietitians, respectively (Appendix 2, available at www.cmaj.ca/lookup/suppl/doi:10.1503/ cmaj.181173/-/DC1).

There was a lower mean rate of hospital admission in the intervention group compared with the control group (mean \pm SD of $0.09 \pm 0.33$ v. $0.23 \pm 0.60$; adjusted incidence rate ratios 0.37 [0.18 to 0.77$]$ ) and the odds of having 1 or more hospital admissions was lower for the intervention versus the control group $(6.96 \% \mathrm{v}$. 14.94\%; OR 0.44 [ $95 \% \mathrm{Cl} 0.20$ to 0.95 ]). Fewer people had 1 or more emergency department visits in the intervention group $(8.86 \% \mathrm{v}$. $13.64 \%)$, but the odds of having an emergency department visit were not statistically significantly different $(0.58[95 \% \mathrm{Cl} 0.28$ to 1.20]). At 6 months, fewer medications were used in the intervention compared with the control group (mean \pm SD of $4.77 \pm 3.78 \mathrm{v}$.
$5.39 \pm 3.59$; adjusted incidence rate ratio 0.86 [0.78 to 0.96]). Seven hospital admissions (none resulting from adverse effects) were related to ambulatory care-sensitive conditions for chronic disease (3 intervention, 4 control) (Appendix 3, available at www. cmaj.ca/lookup/suppl/doi:10.1503/cmaj.181173/-/DC1).

Eleven critical incidents reported to the volunteer coordinator during home visits included mental health issues $(n=5)$ involving stress, suicidal ideation, extreme sadness, living conditions (bedbugs, cockroaches, hoarding) ( $n=3)$, privacy concerns $(n=1)$, visible physical distress $(n=1)$, and loss of a driver's licence from follow-up of an abnormal clock drawing $(n=1)$. The latter was perceived as harm from the patient's perspective.

Subgroup analyses found that people aged $70-79$ years reported greater improvements in comprehensiveness of health care received compared with those aged 80 and older. People married or common law who received the intervention were less likely to have had falls than those who were divorced, separated, widowed or single. People with 2 or fewer chronic conditions were more likely to attain health goals compared with those with 3 or more chronic conditions. No other subgroup comparisons generated statistically significant differences.

Our implementation evaluation conducted with those involved in the intervention (patients, volunteers, health care providers) showed that the most common clinically important alert generated was suboptimal physical activity $(78.5 \%$ of 
Table 3: Goal attainment and other patient-reported measures

\begin{tabular}{|c|c|c|c|c|c|}
\hline \multirow[b]{2}{*}{ Variable } & \multicolumn{2}{|c|}{ Intervention, $\boldsymbol{n}(\%)^{\star}$} & \multicolumn{2}{|c|}{ Control, $n(\%)^{*}$} & \multirow[b]{2}{*}{$\begin{array}{l}\text { Effect estimate } \\
\qquad(95 \% \mathrm{CI})\end{array}$} \\
\hline & $\begin{array}{c}\text { Baseline } \\
n=158\end{array}$ & $\begin{array}{c}6 \mathrm{mo} \\
n=140\end{array}$ & $\begin{array}{c}\text { Baseline } \\
n=154\end{array}$ & $\begin{array}{c}6 \mathrm{mo} \\
n=138\end{array}$ & \\
\hline $\begin{array}{l}\text { Goal attainment scale score, } \\
\text { mean } \pm \text { SD }\end{array}$ & NA & $57.79 \pm 19.86$ & NA & $58.94 \pm 19.70$ & $-1.50(-6.51$ to 3.50$) \dagger$ \\
\hline $\begin{array}{l}\text { Self-efficacy for managing chronic } \\
\text { disease score, mean } \pm \text { SD }\end{array}$ & $7.56 \pm 1.73$ & $7.91 \pm 1.72$ & $7.55 \pm 1.61$ & $7.75 \pm 1.65$ & $2.34(-2.38$ to 7.06$) \ddagger$ \\
\hline Quality of life (score), mean \pm SD & $0.80 \pm 0.13$ & $0.82 \pm 0.12$ & $0.81 \pm 0.13$ & $0.81 \pm 0.13$ & $0.02(-0.014$ to 0.058$) \ddagger$ \\
\hline \multicolumn{6}{|l|}{ Optimal aging } \\
\hline Poor & $13(8.23)$ & $12(8.57)$ & $12(7.79)$ & $14(10.14)$ & $0.78(0.33$ to 1.84$) \ddagger$ \\
\hline Good & $47(29.75)$ & $49(35.00)$ & $50(32.47)$ & $43(31.16)$ & \\
\hline Very good & $60(37.97)$ & $53(37.86)$ & $57(37.01)$ & $59(42.75)$ & \\
\hline Excellent & $31(19.62)$ & $26(18.57)$ & $27(17.53)$ & $21(15.22)$ & \\
\hline $\begin{array}{l}\text { Patient empowerment, } \\
\text { mean } \pm \text { SD }\end{array}$ & $3.01 \pm 0.80$ & $3.04 \pm 0.88$ & $3.02 \pm 0.76$ & $2.85 \pm 0.94$ & $0.172(-0.02$ to 0.36$)$ \\
\hline Social network score, mean \pm SD & $8.84 \pm 1.52$ & $8.75 \pm 1.52$ & $8.74 \pm 1.61$ & $8.69 \pm 1.53$ & $0.038(-0.25$ to 0.33$)$ \\
\hline Social satisfaction score, mean \pm SD & $18.89 \pm 2.41$ & $18.96 \pm 2.87$ & $19.19 \pm 2.37$ & $19.04 \pm 2.76$ & $0.102(-0.35$ to 0.55$)$ \\
\hline \multicolumn{6}{|l|}{ Access to health care resources } \\
\hline No difficulty & $128(81.01)$ & $117(83.57)$ & $121(78.57)$ & $118(85.51)$ & 1.173 (0.594 to 2.317$)$ ฯ \\
\hline Difficulty once & $16(10.13)$ & $16(11.43)$ & $16(10.39)$ & $12(8.70)$ & \\
\hline Difficulty several times & $9(5.70)$ & $6(4.29)$ & $9(5.84)$ & $7(5.07)$ & \\
\hline Comprehensiveness, mean \pm SD & $7.22 \pm 2.86$ & $7.41 \pm 3.29$ & $7.85 \pm 2.89$ & $7.14 \pm 3.08$ & $0.37(-0.42$ to 1.16$)$ \\
\hline Patient-centredness, mean \pm SD & $2.76 \pm 0.77$ & $2.72 \pm 0.83$ & $2.71 \pm 0.75$ & $2.60 \pm 0.82$ & $0.103(-0.071$ to 0.276$)$ \\
\hline Satisfaction with health care, mean \pm SD & $8.61 \pm 1.71$ & $8.44 \pm 2.01$ & $8.67 \pm 1.38$ & $8.55 \pm 1.86$ & $-0.11(-0.54$ to 0.31$)$ \\
\hline \multicolumn{6}{|l|}{ Physical activity (measured by the IPAQ) } \\
\hline Total & $2339(3410)$ & $2061(3583)$ & $2303(3197)$ & $1658(1941)$ & $0.464(-0.025$ to 0.953$)$ \\
\hline Vigorous & $863(2043)$ & 739 (1703) & $767(2008)$ & $611(1278)$ & $0.681(-0.199$ to 1.561$)$ \\
\hline Moderate & $897(1387)$ & $650(1688)$ & $978(1891)$ & $603(1078)$ & $0.453(-0.374$ to 1.280$)$ \\
\hline Walking & $592(891)$ & $673(790)$ & $576(808)$ & $455(506)$ & $1.130(0.306$ to 1.953$) \dagger$ \\
\hline Moderate or vigorous & 1754 (2906) & $1389(3109)$ & 1731 (2959) & $1210(1784)$ & $0.689(-0.127$ to 1.505$)$ \\
\hline Minutes sitting & $360(193)$ & $319(162)$ & $337(175)$ & 342 (149) & $-0.111(-0.218$ to -0.005$)$ \\
\hline \multicolumn{6}{|c|}{ 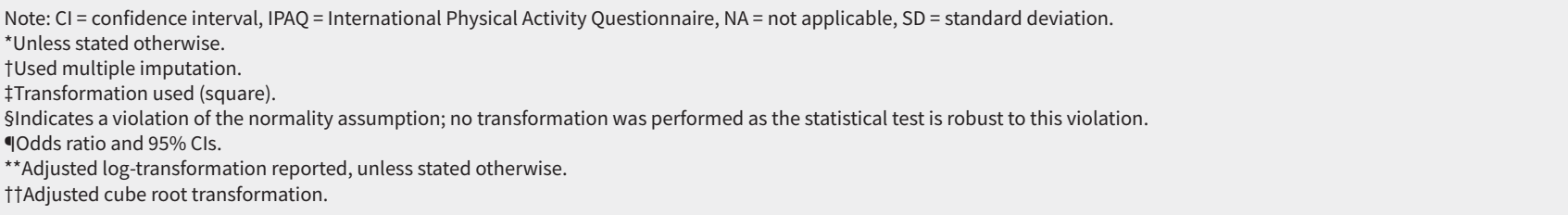 } \\
\hline
\end{tabular}

participants; Appendix 4, available at www.cmaj.ca/lookup/ suppl/doi:10.1503/cmaj.181173/-/DC1), which was notable because it was a common goal and intervention participants spent more time walking. Other key alerts included interest in information about advanced care planning (53.8\%), nutritional risk (46.8\%) and loss of bladder control (35.4\%). Volunteers completed 265 home visits, including 151 initial visits.

\section{Interpretation}

The Health TAPESTRY intervention did not improve the primary outcome of goal attainment, but it did show signals of shifting care usage, by reducing hospital admissions and increasing primary care engagement. Despite inclusion of generally healthy older adults, most participants reported suboptimal physical 
activity and other health risks (e.g., falls) or conditions (e.g., urinary incontinence) not previously identified, and most participants had multimorbidity. The intervention identified care gaps, enabling a range of primary care team members to intervene. We suggest that volunteer home visits explicitly forged connections between patients and the primary care team, eliciting previously unknown information, which activated the design of more tailored plans for care.

Our findings are somewhat consistent with a recent larger trial that also studied a multifaceted, patient-centred primary care approach in people with multimorbidity and found improvements in patient experience measures but no differences in other outcomes, such as quality of life, illness burden or treatment burden, after 15 months. ${ }^{46}$ Although findings are mixed, Health TAPESTRY is aligned with accepted guidance for personal care planning, ${ }^{47,48}$ providing patient-centred or goal-directed care for older adults who are managing multiple chronic condition $\mathrm{s}^{49}$ and Starfield principles of primary care, ${ }^{50-52}$ and, for people with chronic diseases, care-coordination strategies that improve health and outcomes. ${ }^{53}$ The intervention is well aligned with redesigns of the health care system underway in Canada and elsewhere ${ }^{21,54-57}$ and incorporates key elements recommended by the World Health Organization for integrated health care for older people. ${ }^{24}$

Volunteers showed great enthusiasm for and a sense of purpose regarding their role. Community volunteers support the health of communities worldwide ${ }^{15,21,58-60}$ and may benefit themselves from being volunteers. ${ }^{61,62}$ Health TAPESTRY leverages the enormous resource of community volunteers, integrating their work into the formal health care system.

Our study has several strengths. Its pragmatic nature optimizes applicability to real-world practice. Potential participants responded well to invitation letters (patients) and advertisements (volunteers). Volunteer training was feasible. Transmission of information on critical incidents identified by volunteers allowed for early intervention in cases such as elder abuse and mental health. The study evaluated implementation and sustainability ${ }^{63}$ from multiple perspectives. Program implementation costs would need to be substantial to offset costs from the reduction in hospital admissions we found.

\section{Limitations}

This study has several notable limitations. The lack of differences found in measures of patient-reported experiences and patientreported outcomes, including our primary outcome, were likely influenced by higher-than-expected baseline scores, improvements in both groups, variable strength across goal areas, and a short intervention period. Few structured tools are available to assist with goal-directed primary care. ${ }^{64}$ The goal attainment scaling process applies well in multimorbidity, as it is individualized to patients' priority areas. Despite participants choosing their own goals, almost half identified physical activity as a priority goal. However, despite pilot testing of the intervention, it was a challenge for volunteers to discuss goals with patients, given the time needed and the complexity of having such conversations. ${ }^{32} \mathrm{~A}$ longer intervention period may have allowed for more iterative goal-directed care to occur between individuals and their health care team, thus allowing for more effective care to be delivered to the intervention group participants. Furthermore, the control group identifying goals at baseline may have been too strong an intervention itself.

Our study took place within an academic interprofessional team setting, which may limit generalizability to other settings. However, many countries are adopting similar interdisciplinary primary care team approaches. Study participants were generally healthy; implementation and outcomes may be different in those more vulnerable. Of persons approached to participate, $82 \%$ declined to do so, which may have contributed to a healthier study sample. Finally, the reduction in medication use was discovered in exploratory analyses and needs further confirmation.

\section{Conclusion}

Health TAPESTRY did not improve goal attainment and many patient-reported outcomes or experiences, but did improve some clinically important indicators and shows some signals of shifting from reactive care to proactive and preventive care. Further evaluation of Health TAPESTRY mechanisms will help us understand effective components and costs and consequences.

\section{References}

1. Starfield B, Shi L, Macinko J. Contribution of primary care to health systems and health. Milbank Q 2005;83:457-502.

2. Macinko J, Starfield B, Shi LY. The contribution of primary care systems to health outcomes within Organization for Economic Cooperation and Development (OECD) countries, 1970-1998. Health Serv Res 2003;38:831-65.

3. Kuluski K, Ho JW, Hans PK, et al. Community care for people with complex care needs: bridging the gap between health and social care. Int J Integr Care 2017;17:2.

4. Tinetti ME, Fried TR, Boyd CM. Designing health care for the most common chronic condition - multimorbidity [published erratum in JAMA 2012;308:238]. JAMA 2012;307:2493-4

5. Martínez J, Henderson D, Martí T, et al. Benchmarking integrated health and social care information systems in Europe. Int J Integr Care 2016;16:A237. doi: 10.5334/ ijic. 2785 .

6. Primary health care. Toronto: Health Council of Canada; 2005.

7. Barrett J, Curran V, Glynn L, et al. CHSRF synthesis: interprofessional collaboration and quality primary healthcare. Ottawa: Canadian Health Services Research Foundation; 2007.

8. Körner M, Bütof S, Müller C, et al. Interprofessional teamwork and team interventions in chronic care: a systematic review. J Interprof Care 2016;30:15-28.

9. Milani RV, Lavie CJ. Health care 2020: reengineering health care delivery to combat chronic disease. Am J Med 2015;128:337-43.

10. Ciapponi A, Lewin S, Herrera CA, et al. Delivery arrangements for health systems in low-income countries: an overview of systematic reviews. Cochrane Database Syst Rev 2017;9:CD011083.

11. Jones SS, Rudin RS, Perry T, et al. Health information technology: an updated systematic review with a focus on meaningful use. Ann Intern Med 2014;160: 48-54.

12. Kaczorowski J, Chambers LW, Dolovich L, et al. Improving cardiovascular health at population level: 39 community cluster randomised trial of Cardiovascular Health Awareness Program (CHAP). BMJ 2011;342:d442.

13. Mold F, de Lusignan S, Sheikh A, et al. Patients' online access to their electronic health records and linked online services: a systematic review in primary care. $\mathrm{Br} \mathrm{J}$ Gen Pract 2015;65:e141-51. 
14. Trump LJ, Mendenhall TJ. Community health workers in diabetes care: a systematic review of randomized controlled trials. Fam Syst Health 2017;35:320-40.

15. Wilson DM, Justice C, Thomas R, et al. End-of-life care volunteers: a systematic review of the literature. Health Serv Manage Res 2005;18:244-57.

16. Hallett C, Klug G, Lauber C, et al. Volunteering in the care of people with severe mental illness: a systematic review. BMC Psychiatry 2012;12:226.

17. Hall CL, Brooke J, Pendlebury ST, et al. What is the impact of volunteers providing care and support for people with dementia in acute hospitals? A systematic review. Dementia 2017 Jan. 1 [Epub ahead of print]. doi: 10.1177/1471301217713325.

18. Gougeon L, Johnson J, Morse H. Interprofessional collaboration in health care teams for the maintenance of community-dwelling seniors' health and well-being in Canada: a systematic review of trials. J Interprof Educ Pract 2017;7:29-37. doi: 10.1016/j.xjep.2017.02.004.

19. Smith SM, Wallace E, O'Dowd T, et al. Interventions for improving outcomes in patients with multimorbidity in primary care and community settings. Cochrane Database Syst Rev 2016;3:CD006560.

20. March S, Torres E, Ramos M, et al. Adult community health-promoting interventions in primary health care: a systematic review. Prev Med 2015;76(Suppl):S94-104.

21. Gilburt H, Buck D, South J. Volunteering in general practice: opportunities and insights. London: UK: The King's Fund; 2018.

22. Joshi R, Alim M, Kengne AP, et al. Task shifting for non-communicable disease management in low and middle income countries - a systematic review. PLoS One 2014;9:e103754.

23. Ohnmar, Tun-Min, San-Shwe, et al. Effects of malaria volunteer training on coverage and timeliness of diagnosis: a cluster randomized controlled trial in Myanmar. Malar J 2012;11:309.

24. Integrated care for older people: guidelines on community-level interventions to manage declines in intrinsic capacity. Geneva: World Health Organization; 2017.

25. Bloom DE, Chatterji S, Kowal P, et al. Macroeconomic implications of population ageing and selected policy responses. Lancet 2015;385:649-57.

26. Dolovich $\mathrm{L}$, Oliver $\mathrm{D}$, Lamarche $\mathrm{L}$, et al. A protocol for a pragmatic randomized controlled trial using the Health Teams Advancing Patient Experience: strengthening quality (Health TAPESTRY) platform approach to promote person-focused primary healthcare for older adults. Implement Sci 2016;11:49.

27. Valaitis R, Longaphy J, Nair K, et al. Persona-scenario exercise for codesigning primary care interventions. Can Fam Physician 2014;60:294-6.

28. Santaguida P, Dolovich L, Oliver D, et al. Protocol for a Delphi consensus exercise to identify a core set of criteria for selecting health related outcome measures (HROM) to be used in primary health care. BMC Fam Pract 2018;19:152.

29. Oliver D, Dolovich L, Lamarche L, et al. A volunteer program to connect primary care and the home to support the health of older adults: a community case study. Front Med (Lausanne) 2018;5:48.

30. Kiresuk TJ, Smith A, Cardillo JE, editors. Goal attainment scaling: applications, theory, and measurement. Hillsdale (NJ): Lawrence Erlbaum Associates Inc.; 1994.

31. Rushton PW, Miller WC. Goal attainment scaling in the rehabilitation of patients with lower-extremity amputations: a pilot study. Arch Phys Med Rehabil 2002;83: 771-5.

32. Javadi D, Lamarche L, Avilla E, et al. Feasibility study of goal setting discussions between older adults and volunteers facilitated by an eHealth application: development of the Health TAPESTRY approach. Pilot Feasibility Stud 2018;4:184.

33. Lorig K, Chastain RL, Ung E, et al. Development and evaluation of a scale to measure perceived self-efficacy in people with arthritis. Arthritis Rheum 1989;32:37-44.

34. Szende A, Williams A, editors. Measuring self-reported population health: an international perspective based on EQ-5D. Rotterdam (Netherlands): EuroQol Group; 2004.

35. Raina PS, Wolfson C, Kirkland SA, et al. The Canadian longitudinal study on aging (CLSA). Can J Aging 2009;28:221-9.

36. Wardian J, Robbins D, Wolfersteig W, et al. Validation of the DSSI-10 to measure social support in a general population. Res Soc Work Pract 2013;23:100-6. doi: $10.1177 / 1049731512464582$
37. Bédard M, Molloy DW, Squire L, et al. The Zarit Burden Interview: a new short version and screening version. Gerontologist 2001;41:652-7.

38. Wong S, Langton J, Katz A, et al. Promoting cross-jurisdictional primary health care research: Developing a set of common indicators across 12 communitybased primary health care teams in Canada. Primary Health Care Research \& Development 2019;20:E7.

39. Craig CL, Marshall AL, Sjöström M, et al. International physical activity questionnaire: 12-country reliability and validity. Med Sci Sports Exerc 2003;35:1381-95.

40. Lee PH, Macfarlane DJ, Lam TH, et al. Validity of the International Physical Activity Questionnaire Short Form (IPAQ-SF): a systematic review. Int J Behav Nutr Phys Act 2011;8:115

41. Patient-centred care [policy paper]. Ontario Medical Association; 2010.

42. Demetrios M, Gorelik A, Louie J, et al. Outcomes of ambulatory rehabilitation programmes following botulinum toxin for spasticity in adults with stroke. J Rehabil Med 2014;46:730-7.

43. Rockwood K, Howlett S, Stadnyk K, et al. Responsiveness of goal attainment scaling in a randomized controlled trial of comprehensive geriatric assessment. J Clin Epidemiol 2003;56:736-43.

44. Rockwood K, Stolee P, Fox RA. Use of goal attainment scaling in measuring clinically important change in the frail elderly. J Clin Epidemiol 1993;46:1113-8.

45. Little RJA, Rubin DB. Statistical analysis with missing data, 2nd edition. Hoboken (NJ): John Wiley \& Sons Inc.; 2002.

46. Salisbury C, Man MS, Bower $\mathrm{P}$, et al. Management of multimorbidity using a patientcentred care model: a pragmatic cluster-randomised trial of the 3D approach. Lancet 2018;392:41-50.

47. Coulter A, Entwistle VA, Eccles A, et al. Personalised care planning for adults with chronic or long-term health conditions. Cochrane Database Syst Rev 2015;(3): CD010523.

48. Tinetti ME, Naik AD, Dodson JA. Moving from disease-centered to patient goals-directed care for patients with multiple chronic conditions: patient value-based care. JAMA Cardiol 2016;1:9-10.

49. American Geriatrics Society Expert Panel on the Care of Older Adults with Multimorbidity. Patient-centered care for older adults with multiple chronic conditions: a stepwise approach from the American Geriatrics Society: American Geriatrics Society Expert Panel on the Care of Older Adults with Multimorbidity. J Am Geriatr Soc 2012;60:1957-68.

50. Starfield B. Is primary care essential? Lancet 1994;344:1129-33.

51. Starfield B, Shi L. Policy relevant determinants of health: an international perspective. Health Policy 2002;60:201-18.

52. Starfield B. Toward international primary care reform. CMAJ 2009;180:1091-2.

53. Kastner M, Cardoso R, Lai Y, et al. Effectiveness of interventions for managing multiple high-burden chronic diseases in older adults: a systematic review and meta-analysis. CMAJ 2018;190:E1004-12.

54. Joint principles of the patient-centered medical home. Leawood (KS): American Academy of Family Physicians; 2007.

55. Patients First: Action Plan for Health Care. Ontario Ministry of Health and LongTerm Care; modified 2018 Dec. 7. Available: www.health.gov.on.ca/en/ms/ ecfa/healthy_change/ (accessed 2018 Apr. 25).

56. Transforming primary care: safe, proactive, personalised care for those who need it most. London (UK): Department of Health, NHS England; 2014.

57. Yiu V, Woods S, Gordon D, et al. The Patients First Strategy. Edmonton: Alberta Health Services; 2015.

58. Casiday R, Kinsman E, Fisher C, et al. Volunteering and health: What impact does it really have? [monograph (project report)]. London (UK): National Council for Voluntary Organisations; 2008.

59. Webel AR, Okonsky J, Trompeta J, et al. A systematic review of the effectiveness of peer-based interventions on health-related behaviors in adults. Am J Public Health 2010;100:247-53. 
60. Naylor C, Mundle C, Weaks L, et al. Volunteering in health care: securing a sustainable future. London (UK): The King's Fund; 2013:1-40.

61. Anderson ND, Damianakis T, Kroger E, et al.; BRAVO Team. The benefits associated with volunteering among seniors: a critical review and recommendations for future research. Psychol Bull 2014;140:1505-33.

62. Jenkinson CE, Dickens AP, Jones K, et al. Is volunteering a public health intervention? A systematic review and meta-analysis of the health and survival of volunteers. BMC Public Health 2013;13:773.
63. Kastner M, Sayal R, Oliver D, et al. Sustainability and scalability of a volunteerbased primary care intervention (Health TAPESTRY): a mixed-methods analysis. BMC Health Serv Res 2017;17:514.

64. Mangin D, Stephen G, Bismah V, et al. Making patient values visible in health care: a systematic review of tools to assess patient treatment priorities and preferences in the context of multimorbidity. BMJ Open 2016;6:e010903.
Competing interests: Tracey Carr, Lisa Dolovich, Dee Mangin, David Price and Cathy Risdon report receiving grants from Health Canada and the Government of Ontario during the conduct of this study.

This article has been peer reviewed.

Affiliations: Departments of Family Medicine (Dolovich, Oliver, Lamarche, Agarwal, Carr, Javadi, Mangin, Risdon, Price), Medicine (Papaioannou), and Health Research Methods, Evidence and Impact (Thabane, Foster, Griffith, Raina, Santaguida, Papaioannou), McMaster Institute for Research on Aging (Raina), Schools of Rehabilitation Science (Richardson) and of Nursing (Valaitis, Ploeg), McMaster University; Hamilton Health Sciences (Price), Hamilton, Ont.; Leslie Dan Faculty of Pharmacy (Dolovich); University of Toronto; Institute of Health Policy, Management and Evaluation (Kastner), Dalla Lana School of Public Health, University of Toronto; Li Ka Shing Knowledge Institute of St. Michael's Hospital (Straus), Toronto, Ont.

Contributors: All authors contributed to the concept and design of the study. Lisa Dolovich, Larkin Lamarche and Gary Foster drafted the manuscript and all authors revised it critically for important intellectual content. David Price and Lisa Dolovich obtained funding. Lisa Dolovich and Doug Oliver directed all aspects of study execution. Lisa Dolovich, Doug Oliver Larkin Lamarche, Ruta Valaitis and Dena Javadi oversaw data acquisition. Lisa Dolovich, Doug Oliver, Larkin Lamarche, Lehana Thabane, Ruta Valaitis and Gary Foster were responsible for data analysis. All authors contributed to interpretation of data for the work, gave final approval of the version to be published and agreed to be accountable for all aspects of the work.
Funding: Health Canada (grant no. 6817-06-2013/5570001), Government of Ontario (grant no. 06547 for INSPIRE-PHC), McMaster University and McMaster Family Health Organization. The funders of the study had no role in study design, data collection, data analysis, data interpretation, or writing of the report. The corresponding author had full access to all the data in the study and had final responsibility for the decision to submit for publication.

Data sharing: Individual participant data that underlie the results reported in this article will be made available on request after deidentification, beginning 6 months after article publication to investigators whose proposed use of the data has been approved by an independent review committee.

Acknowledgements: The authors thank Ernie Avilla, Mehreen Bhamani, David Chan, Laura Cleghorn, Jessica Gaber, Jennifer Longaphy, Kalpana Nair, Lynda Nash, Fiona Parascandalo, Anubha Sant, Raied Siddiqui and Linda Xie for their contributions to the development of Health TAPESTRY. They also thank the patients, caregivers, clinic staff and health care providers and volunteers for their incredible work in realizing the Health TAPESTRY program.

Disclaimer: Monika Kastner is an associate editor for CMAJ and was not involved in the editorial decision-making process for this article.

Accepted: Apr. 8, 2019

Correspondence to: Lisa Dolovich, lisa.dolovich@utoronto.ca 